\title{
NanoPET imaging of [18F]fluoromisonidazole uptake in experimental mouse tumours
}

\section{Journal Article}

\section{Author(s):}

Wyss, Matthias T.; Honer, Michael; Schubiger, Pius A.; Ametamey, Simon M.

Publication date:

2006-03

\section{Permanent link:}

https://doi.org/10.3929/ethz-b-000002155

\section{Rights / license:}

In Copyright - Non-Commercial Use Permitted

\section{Originally published in:}

European Journal of Nuclear Medicine and Molecular Imaging 33(3), https://doi.org/10.1007/s00259-005-1951-4 


\title{
NanoPET imaging of $\left[{ }^{18} \mathrm{~F}\right]$ fluoromisonidazole uptake in experimental mouse tumours
}

\author{
Matthias T. Wyss ${ }^{1,2}$, Michael Honer ${ }^{1}$, Pius A. Schubiger ${ }^{1}$, Simon M. Ametamey ${ }^{1}$ \\ ${ }^{1}$ Center for Radiopharmaceutical Science of ETH, PSI and USZ, Paul Scherrer Institute, Villigen, Switzerland \\ 2 PET Center, Division of Nuclear Medicine, University Hospital Zurich, Rämistrasse 100, 8091 Zurich, Switzerland
}

Received: 26 May 2005 / Accepted: 11 August 2005 / Published online: 29 October 2005

(C) Springer-Verlag 2005

\begin{abstract}
Purpose: The purpose of this study was to assess the potential and utility of ultra-high-resolution hypoxia imaging in various murine tumour models using the established hypoxia PET tracer $\left[{ }^{18} \mathrm{~F}\right]$ fluoromisonidazole $\left(\left[{ }^{18} \mathrm{~F}\right] \mathrm{FMISO}\right)$.

Methods: $\left[{ }^{18} \mathrm{~F}\right]$ FMISO PET imaging was performed with the dedicated small-animal PET scanner NanoPET (Oxford Positron Systems) and ten different human tumour xenografts in nude mice as well as B16 melanoma tumours in syngeneic Balb/c mice. For comparison, $\left[{ }^{18} \mathrm{~F}\right]$ fluorodeoxyglucose ( $\left.\left[{ }^{18} \mathrm{~F}\right] \mathrm{FDG}\right)$ PET scans were also performed in the mice bearing human tumour xenografts.

Results: In 10 out of 11 experimental tumour models, $\left[{ }^{18} \mathrm{~F}\right]$ FMISO PET imaging allowed clear-cut visualisation of the tumours. Inter- and intratumoural heterogeneity of tracer uptake was evident. In addition to average TMRR (tumour-to-muscle retention ratio including all voxels in a volume of interest (VOI)), the parameters $\mathrm{TMRR}_{75 \%}$ and $\mathrm{TMRR}_{5}$ (tumour-to-muscle retention ratio including voxels of $75 \%$ or more of the maximum radioactivity in a VOI and the five hottest pixels, respectively) also served as measures for quantifying the heterogeneous $\left[{ }^{18} \mathrm{~F}\right]$ FMISO uptake in the tumours. The variability observed in $\left[{ }^{18} \mathrm{~F}\right] \mathrm{FMISO}$ uptake was related neither to tumour size nor to the injected mass of the radiotracer. The pattern of normoxic and hypoxic regions within the human tumour xenografts, however, correlated with glucose metabolism as revealed by comparison of $\left[{ }^{18} \mathrm{~F}\right] \mathrm{FDG}$ and $\left[{ }^{18} \mathrm{~F}\right] \mathrm{FMISO}$ images.
\end{abstract}

Conclusion: This study demonstrates the feasibility and utility of $\left[{ }^{18} \mathrm{~F}\right] \mathrm{FMISO}$ for imaging murine tumour models using NanoPET.

Keywords: NanoPET - Tumour hypoxia -

$\left[{ }^{18}\right.$ F $]$ Fluoromisonidazole $-\left[{ }^{18} \mathrm{~F}\right]$ Fluorodeoxyglucose Murine tumour models

Matthias T. Wyss (-)

PET Center, Division of Nuclear Medicine,

University Hospital Zurich,

Rämistrasse 100,

8091 Zurich, Switzerland

e-mail: matthias.wyss@usz.ch

Tel.: +41-44-2559434, Fax: +41-44-2554414
Eur J Nucl Med Mol Imaging (2006) 33:311-318

DOI 10.1007/s00259-005-1951-4

\section{Introduction}

Hypoxia occurs in a variety of human tumours [1-5]. It presumably results from rapid tumour growth and disorganised tumour vasculature as well as inadequate blood flow. In the early 1950s, radiation therapists observed that tumour oxygenation plays a role in the response to radiotherapy [6]. Tumour hypoxia reduces local tumour control by radiation therapy [7] and in addition predicts general treatment outcome following radio- and chemotherapy in a number of human cancers $[8,9]$. Furthermore, hypoxia is associated with a more aggressive malignant phenotype [10].

The assessment of tumour oxygenation is important for the understanding of treatment effects in tumours. Because tumour hypoxia cannot be predicted by commonly used clinical parameters such as size, grade or histology of the tumour [11], methods for the evaluation of tumour hypoxia are crucial.

Numerous invasive methods for measuring tissue hypoxia exist, e.g. the Eppendorf needle electrode measurement [12-16], the comet assay [17] and immunohistochemical methods $[15,18-20]$. However, these methods are limited by their invasiveness, their inability to provide a complete three-dimensional representation of tumour hypoxia and their applicability only to superficial tumour sites. Among the non-invasive methods for the assessment of tumour oxygenation, positron emission tomography (PET) using radiolabelled nitroimidazoles has yielded the most encouraging results. Several fluorine-18-labelled 2-nitroimidazole derivatives have been described in the literature, e.g. $\left[{ }^{18} \mathrm{~F}\right]$ fluoromisonidazole ([ $\left.{ }^{18} \mathrm{~F}\right]$ FMISO) $[21],\left[{ }^{18} \mathrm{~F}\right]-2-(2-n i t r o-1[\mathrm{H}]$-imidazol-1-yl)$N$-(2,2,3,3,3-pentafluoropropyl)-acetamide ([ $\left.\left.{ }^{18} \mathrm{~F}\right] \mathrm{EF} 5\right)$ $[22,23],\left[{ }^{18} \mathrm{~F}\right]$ fluoroerythronitroimidazole $\left(\left[{ }^{18} \mathrm{~F}\right]\right.$ FETNIM $)$ $[24,25],\left[{ }^{18} \mathrm{~F}\right]$ fluoroazomycinarabinofuranoside $\left(\left[{ }^{18} \mathrm{~F}\right] \mathrm{FAZA}\right)$ $[26]$ and $\left[{ }^{18} \mathrm{~F}\right]$ fluoroetanidazole $\left(\left[{ }^{18} \mathrm{~F}\right] \mathrm{FETA}\right)[27] .\left[{ }^{18} \mathrm{~F}\right]$ 
FMISO remains the PET radioligand most commonly used to image tumour hypoxia and has been applied in several human PET studies [2, 28-30].

Despite the recent development of dedicated smallanimal PET scanners (see reviews [31-33]) and the availability of a large variety of cancer models in rodents, only two studies have described $\left[{ }^{18} \mathrm{~F}\right] \mathrm{FMISO}$ PET in murine tumour models using small-animal PET [34, 35]. However, $\left[{ }^{18} \mathrm{~F}\right] \mathrm{FMISO}$ and small-animal PET could serve as a platform in biomedical research to accelerate the development of new anti-tumour drugs as well as to measure the efficacy of anti-tumour drugs. This could be important for a better understanding of changes in biological parameters (e.g. hypoxia) during treatment.

The aim of this study was to assess the $\left[{ }^{18} \mathrm{~F}\right]$ FMISO uptake pattern in various murine tumours using the dedicated small-animal PET scanner NanoPET and to assess the utility of this modality. Additionally, the influence of increasing amounts of unlabelled FMISO on $\left[{ }^{18} \mathrm{~F}\right] \mathrm{FMISO}$ uptake in B16 melanoma-bearing mice was investigated. Finally, $\left[{ }^{18} \mathrm{~F}\right]$ fluorodeoxyglucose $\left(\left[{ }^{18} \mathrm{~F}\right] \mathrm{FDG}\right)$ studies were performed in mice bearing human tumour xenografts to analyse the relationship between glucose metabolism and oxygenation status of the tumour.

\section{Materials and methods}

\section{Animals and tumour models}

Animal care and all experimental procedures were approved by the Swiss Federal Veterinary Office. All animal work was performed by licensed investigators.

Animals were kept in cages under standardised conditions of light and temperature and with free access to food and water.

As models, ten human tumour xenografts in nude mice (the nasopharyngeal carcinoma cell line KB-31; the non-small cell lung carcinoma cell lines A549, H520 and H596; the glioblastoma cell line U87; the prostate cancer cell lines PC-3 and DU-145; the renal cell carcinoma cell line Caki; the neuroblastoma cell line SK-N-BE and the urinary bladder carcinoma cell line CLS-2) and B16 melanoma tumours in syngeneic Balb/c mice were used. Tumour cells harvested from exponentially growing in vitro cultures were injected subcutaneously into the dorsum subcutis of female nude mice (for human tumour xenografts) or female Balb/c mice (for B16 melanoma) with $3 \times 10^{6}$ tumour cells in $200 \mu \mathrm{l}$ PBS. After 7-14 days, animals were selected for experiments, when tumour weight was at least $100 \mathrm{mg}$.

\section{Radiotracer preparation}

The radiosynthesis of $\left[{ }^{18} \mathrm{~F}\right] \mathrm{FMISO}$ was carried out according to the two-step procedure reported by Lim and Berridge [36]. The total synthesis time was approximately $120 \mathrm{~min}$, and radiochemical purity was greater than $99 \%$ assayed by high-performance liquid chromatography. Specific radioactivities obtained immediately after the syntheses were always greater than $30 \mathrm{GBq} / \mu \mathrm{mol}$, corresponding to a total of $2-10 \mu \mathrm{g} / \mathrm{ml}$ of unlabelled FMISO. To obtain various specific activities of $\left[{ }^{18} \mathrm{~F}\right] \mathrm{FMISO}$ for the investigation of the influence of increasing amounts of unlabelled FMISO on $\left[{ }^{18} \mathrm{~F}\right]$ FMISO uptake, defined amounts of unlabelled fluoromisonidazole were added to the $\left[{ }^{18} \mathrm{~F}\right]$ FMISO preparations after synthesis.

$\left[{ }^{18} \mathrm{~F}\right] \mathrm{FDG}$ was obtained from the commercial production of University Hospital Zurich.

\section{PET scanning}

PET experiments were performed on the 16-module variant of the NanoPET tomograph (Oxford Positron Systems; Weston-on-theGreen, UK) with performance characteristics as described elsewhere $[37,38]$. Briefly, the camera is made up of four detector backs each comprising four HIDAC (high-density avalanche chamber) modules. Each module consists of a multi-wire proportional chamber with the addition of lead layers containing a matrix of holes $0.4 \mathrm{~mm}$ in diameter and $0.5 \mathrm{~mm}$ pitch. The field of view is $280 \mathrm{~mm}$ axially and $170 \mathrm{~mm}$ in diameter, allowing for the acquisition of whole-body images of mice in a single bed position. Animals were anaesthetised with isoflurane (Forene, Abbott Laboratories; North Chicago, USA) in an air/oxygen mixture, fixed in the prone position with adhesive tape and positioned in the camera such that the tumour was placed near the centre of the field of view. Depth of anaesthesia was monitored by measuring respiratory frequency. Body temperature was controlled by a rectal probe and kept at $\sim 37^{\circ} \mathrm{C}$ by a thermocoupler and a heated air stream. For the $\left[{ }^{18} \mathrm{~F}\right] \mathrm{FMISO}$ studies, the PET scan was started 90 min after the radiotracer injection into the awake animal and represented the reference time point for all further procedures and decay corrections. $\left[{ }^{18} \mathrm{~F}\right] \mathrm{FMISO}$ (13.2-29.9 MBq; max. $200 \mu \mathrm{l}$ ) was injected via a lateral tail vein. For each human tumour xenograft model, one animal was scanned, with the exception of the Caki $(n=4)$ and the CLS-2 tumour models $(n=3)$. The analysis of the melanoma B16 model included 12 animals (only experiments with unmodified $\left[{ }^{18} \mathrm{~F}\right] \mathrm{FMISO}$ preparation were included). For studying the mass effect of unlabelled FMISO, six animals of the B16 melanoma tumour model group were each examined three times on three consecutive days using a formulated solution of $\left[{ }^{18} \mathrm{~F}\right]$ FMISO containing different amounts of unlabelled FMISO. In ten animals (one each of the human tumour xenografts), additional NanoPET imaging was performed $30 \mathrm{~min}$ after the injection of 13.9-24.7 MBq $\left[{ }^{18} \mathrm{~F}\right] \mathrm{FDG}$. $\left[{ }^{18} \mathrm{~F}\right] \mathrm{FMISO}$ and $\left[{ }^{18} \mathrm{~F}\right] \mathrm{FDG}$ PET data were acquired within several days of each other.

All PET data were acquired during $30 \mathrm{~min}$ in list mode and reconstructed using the OPL-EM algorithm [39] with a voxel size of $0.3 \mathrm{~mm}$ and a matrix size of $120 \times 120 \times 200$. Reconstruction did not include scatter, random and attenuation correction.

\section{PET data quantification}

Regions of interest (ROIs) were defined for the tumour on all coronal planes containing tumour tissue, yielding a volume of interest (VOI). Reference tissue ROIs were drawn on five to ten subsequent coronal planes containing muscle tissue at the contralateral forelimb. ROIs were manually defined using the dedicated software PMOD ([40]; http:// www.pmod.com; PMOD Technologies Ltd., Adliswil, Switzerland).

For the quantification of $\left[{ }^{18} \mathrm{~F}\right] \mathrm{FMISO}$ uptake, we based our calculation on the tumour-to-muscle retention ratio (TMRR). In analogy to the method described by Koh and co-workers [21], a tumour pixel with a tumour-to-muscle retention ratio $\geq 1.4$ during the image acquisition interval was used to define the presence of hypoxia. Additionally, TMRR calculated for pixels of $75 \%$ or more of the maximum radioactivity in the VOI $\left(\mathrm{TMRR}_{75 \%}\right)[41]$, TMRR based on the five hottest pixels of the tumour VOI $\left(\mathrm{TMRR}_{5}\right)$ and fractional hypoxic volumes (FHVs) were computed to assess $\left[{ }^{18} \mathrm{~F}\right]$ FMISO uptake. FHV was defined as the percentage of pixels within a 
tumour volume with a TMRR $\geq 1.4$. To quantify the $\left[{ }^{18} \mathrm{~F}\right] \mathrm{FDG}$ uptake, the measured tissue activity concentration (counts $\times \mathrm{ml}^{-1}$ ) was divided by the injected activity in $\mathrm{kBq}$ per gram of body weight $\left(\mathrm{kBq} \times \mathrm{g}^{-1}\right)$ to give a normalised activity concentration.

\section{Statistical analysis}

The following parameters were used for image analysis:

- $\left[{ }^{18}\right.$ F]FMISO: TMRR, TMRR $75 \%$, TMRR $_{5}$ and FHV

- $\left[{ }^{18}\right.$ F]FDG: normalised activity concentration $\left(\right.$ counts $\times \mathrm{ml}^{-1}$ )/ $\left(\mathrm{kBq}^{\circ} \mathrm{g}^{-1}\right)$

Pearson coefficients of correlation were calculated in order to measure the degree of linear dependence between oxygenation values based on PET data and other parameters such as volume, injected mass of unlabelled FMISO and glucose metabolism. Pearson correlation coefficients $r>0.7$ and $r<-0.7$ were interpreted as a strong positive or negative correlation, respectively. Coefficients between 0.3 and -0.3 were regarded as no correlation. A $P$ value smaller than 0.05 denoted statistical significance. Linear regression analysis was performed for all 11 tumour models investigated. For tumour models where more than one animal was available, the first scanned animal was included in the statistical analysis.

\section{Results}

\section{${ }^{18}$ F]FMISO uptake}

Visual inspection of coronal image slices reflecting the mean radioactivity concentration over the time from 90 to $120 \mathrm{~min}$ after injection of $\left.{ }^{18} \mathrm{~F}\right] \mathrm{FMISO}$ showed high radioactivity uptake by the liver, intestine, kidney and bladder. In all experimental tumour models examined (except the Caki model), tumours were clearly visualised (Fig. 1) with a more or less heterogeneous uptake pattern. High count density in the rim of the tumour surrounding a central part of low radioactivity uptake, most probably reflecting necrotic tissue, was a commonly observed uptake pattern in the examined tumour models (Fig. 1a-e). The second observed pattern was a spotty distribution of $\left[{ }^{18} \mathrm{~F}\right] \mathrm{FMISO}$, probably indicating hypoxic cells adjacent to small necrotic foci scattered in the tumour (Fig. 1f,g,i,k and 1). A broad range of TMRR values between 1.00 and 5.70 were obtained for the different tumour models (Table 1). Detailed analysis of selected tumour models (Caki, CLS-2, B16 melanomas) showed large variability in $\left[{ }^{18} \mathrm{~F}\right]$ FMISO tumour uptake, which was also reflected by the large standard deviations (Table 1).

As expected, tumour ROI analysis based on either $\mathrm{TMRR}_{75 \%}$ or TMRR gave higher values (Table 1) compared with TMRR.

\section{Tracer uptake and tumour volume}

No correlation between tumour volume resulting from VOI analysis and $\left[{ }^{18} \mathrm{~F}\right] \mathrm{FMISO}$ uptake was found when all the different tumour models examined were included in the

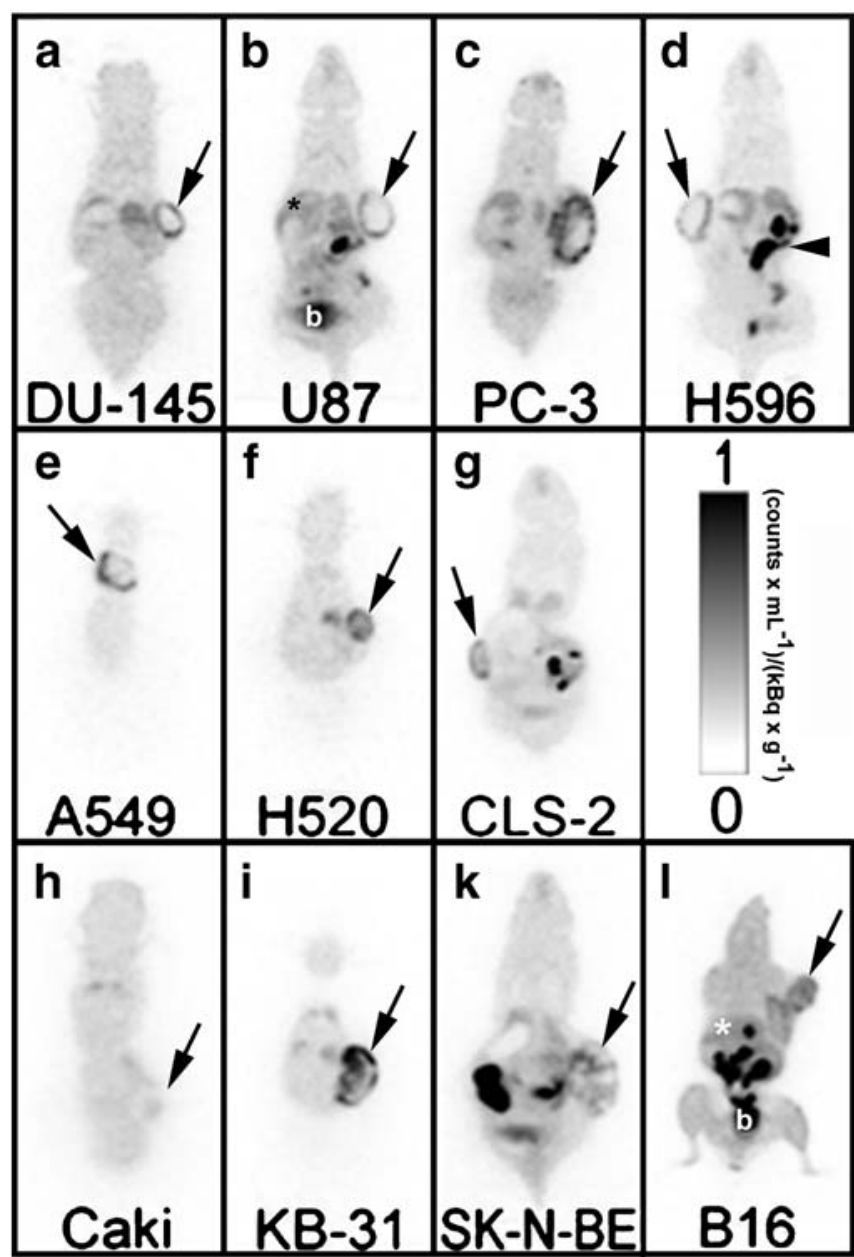

Fig. 1. Coronal whole-body NanoPET images acquired from 90 to $120 \mathrm{~min}$ after injection of $\left[{ }^{18} \mathrm{~F}\right] \mathrm{FMISO}$. The images are representative slices ( $0.3 \mathrm{~mm}$ thickness) through the tumour, with the animal's head at the top. Shown are 11 mice with various subcutaneous tumour models (arrows). The images allow clear-cut visualisation of the tumours in 10 out of the 11 demonstrated animals. Only the Caki tumour model (h) showed low TMRR $(\leq 1.4)$, making the demarcation of the tumour difficult. Note that the heterogeneity of tracer uptake is a common feature among different tumours. *, Liver; arrowhead, intestine; $b$, bladder

analysis, irrespective of the selected parameter of $\left[{ }^{18} \mathrm{~F}\right]$ FMISO uptake $\left(n=11\right.$; TMRR: $r=0.07 ; p>0.05$;MRR $_{75 \%}$ : $r=0.22 ; p>0.05$ TMRR $_{5}: r=0.23 ; p>0.05$; FHV: $r=0.28$; $p>0.05$ ). However, including only the syngeneic $\mathrm{Balb} / \mathrm{c}$ B16 tumour model in the correlation analysis yielded a significant correlation between tracer uptake and tumour volume for $\mathrm{TMRR}_{75 \%}, \mathrm{TMRR}_{5}$ and $\mathrm{FHV}$, though not for TMRR ( $n=12$; TMRR: $r=0.51, p>0.05$ TMRR $_{75 \%}: r=0.72$, $p=0.007$; TMRR $_{5}: r=0.72, p=0.008$; FHV: $r=0.57, p=0.05$ ).

\section{Injected mass and ${ }^{18}$ F]FMISO uptake}

Both visual inspection and semiquantitative analysis revealed no difference in $\left[{ }^{18} \mathrm{~F}\right]$ FMISO tumour uptake for different administered amounts of FMISO up to $20 \mathrm{mg} / \mathrm{ml}$ 
Table 1. $\left[{ }^{18}\right.$ F]FMISO uptake in the examined tumour models

${ }^{*}$ Mean \pm standard deviation

\begin{tabular}{llllll}
\hline Tumour & Mice & TMRR & TMRR $_{75 \%}$ & TMRR $_{5}$ & FHV \\
\hline KB-31 & Nude mice & 5.7 & 9.4 & 11.5 & $>99.9 \%$ \\
H596 & Nude mice & 2.59 & 6 & 7.18 & $85.60 \%$ \\
U87 & Nude mice & 1.93 & 3.64 & 4.36 & $70.70 \%$ \\
H520 & Nude mice & 4.45 & 6.27 & 7.73 & $100 \%$ \\
PC-3 & Nude mice & 3.53 & 6.2 & 7.6 & $97.40 \%$ \\
DU-145 & Nude mice & 2.27 & 4 & 4.8 & $83.80 \%$ \\
A549 & Nude mice & 3.5 & 7.88 & 9.5 & $98.60 \%$ \\
Caki & Nude mice & $1.28 \pm 0.36^{*}$ & $1.61 \pm 0.4^{*}$ & $1.87 \pm 0.44^{*}$ & $9.45 \pm 14.8 \% *(n=4)$ \\
SK-N-BE & Nude mice & 2.48 & 5.44 & 6.72 & $87.10 \%$ \\
CLS-2 & Nude mice & $3.62 \pm 0.06^{*}$ & $5.48 \pm 0.65^{*}$ & $6.6 \pm 0.64^{*}$ & $98.9 \pm 1.1 \% *(n=3)$ \\
B16 & Balb c & $2.04 \pm 0.83^{*}$ & $4.37 \pm 2.27^{*}$ & $5.27 \pm 2.76^{*}$ & $66.2 \pm 33.5 \% *(n=12)$ \\
\hline
\end{tabular}

(Fig. 2). Specifically, no significant correlation between $\left[{ }^{18}\right.$ F]FMISO uptake and injected mass of FMISO was evident using the various methods of calculation $(n=24$; TMRR: $r=0.05 ; p>0.1 ; \mathrm{TMRR}_{75 \%}: r=0.22 ; p>0.1$ TMRR $_{5}: r=0.22$; $p>0.1$; FHV: $r=0.20 ; p>0.1$.

\section{$\left[{ }^{18} \mathrm{~F}\right] F D G$ uptake}

Human tumour xenografts were also evaluated with $\left[{ }^{18} \mathrm{~F}\right]$ FDG in order to compare glucose metabolism with $\left[{ }^{18} \mathrm{~F}\right]$ FMISO uptake. The uptake values for glucose utilisation are shown in Table 2 for all ten models examined. Generally, low FDG uptake was observed in tumour regions with low FMISO uptake and vice versa. The overall distribution pattern of both PET ligands appeared to be similar (Fig. 3). The uptake values of FDG and all parameters used to quantify $\left[{ }^{18} \mathrm{~F}\right] \mathrm{FMISO}$ accumulation exhibited a strong positive correlation $\left(n=10\right.$; TMRR: $r=0.89, p<0.001$; $\mathrm{TMRR}_{75 \%}$ : $r=0.86, p=0.001$ TMRR $_{5}: r=0.86, p=0.001$; FHV: $r=0.77$, $p=0.008)$.

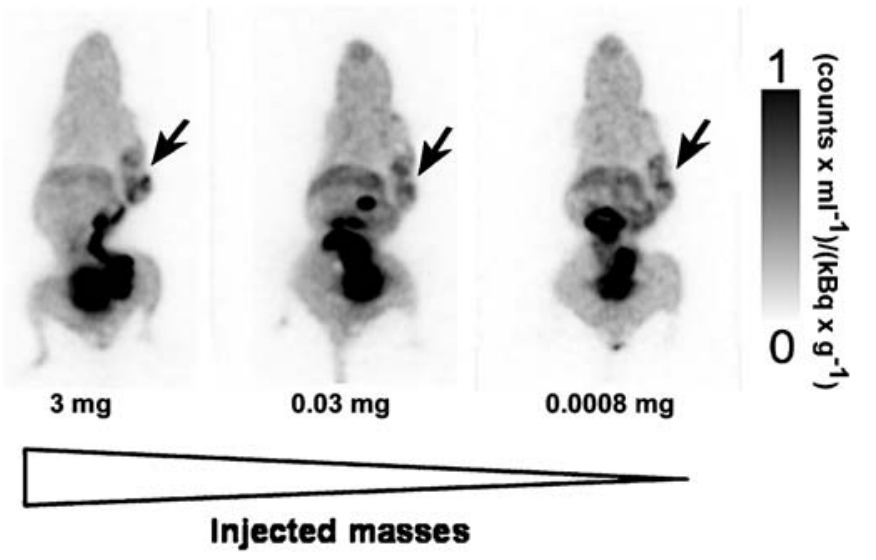

Fig. 2. The same B16 melanoma-bearing animal scanned on three different days after $\left[{ }^{18} \mathrm{~F}\right] \mathrm{FMISO}$ injection with a decreasing injected mass of unlabelled FMISO. Upon visual inspection, no difference in radiotracer uptake or image quality is apparent. The tumour is marked by an arrow

\section{Discussion}

Small-animal PET imaging in oncology represents an excellent tool for preclinical research. First, tumours transplanted in the thigh, shoulder or back of the animal can easily be localised and visualised with high spatial resolution. Second, the animal can be used as its own control, allowing estimations of TMRRs to be made, and finally, small-animal PET systems offer the possibility of longitudinal and serial studies during therapeutic interventions, which enable the monitoring of changes in tumour biology. Thus, non-invasive imaging of small laboratory animals such as mice and rats might help to bridge the gap between preclinical and clinical studies by accelerating the development of new anti-tumour drugs.

Among ${ }^{18} \mathrm{~F}$-labelled tracers mentioned in the Introduction, $\left[{ }^{18} \mathrm{~F}\right] \mathrm{FMISO}$ is currently the most extensively studied hypoxia imaging agent in clinical PET [2, 21, 30, 42, 43]. To the best of our knowledge, this is the first study in which small-animal PET imaging has been used to explicitly describe $\left[{ }^{18} \mathrm{~F}\right]$ FMISO uptake and distribution in various murine tumour models. Four studies examining $\left[{ }^{18} \mathrm{~F}\right]$ FMISO uptake in tumour-bearing mice using PET have been reported [13, 34, 35, 44]. Two of them employed human PET scanners and the tumour ROIs were very small compared with the PET scanner's resolution [13, 44].

Table 2. ${ }^{18}$ F]FDG uptake in the examined tumour models in nude mice ( $n=1$ each)

\begin{tabular}{|c|c|}
\hline Tumour & $\begin{array}{l}\left(\text { Counts } \times \mathrm{ml}^{-1}\right) / \\
\left(\mathrm{kBq} \times \mathrm{g}^{-1}\right)\end{array}$ \\
\hline KB-31 & 0.88 \\
\hline H596 & 0.48 \\
\hline U87 & 0.54 \\
\hline H520 & 0.69 \\
\hline PC-3 & 0.53 \\
\hline $\begin{array}{r}\text { DU- } \\
145\end{array}$ & 0.34 \\
\hline A549 & 0.53 \\
\hline Caki & 0.12 \\
\hline $\begin{array}{l}\text { SK-N- } \\
\text { BE }\end{array}$ & 0.54 \\
\hline CLS-2 & 0.51 \\
\hline
\end{tabular}




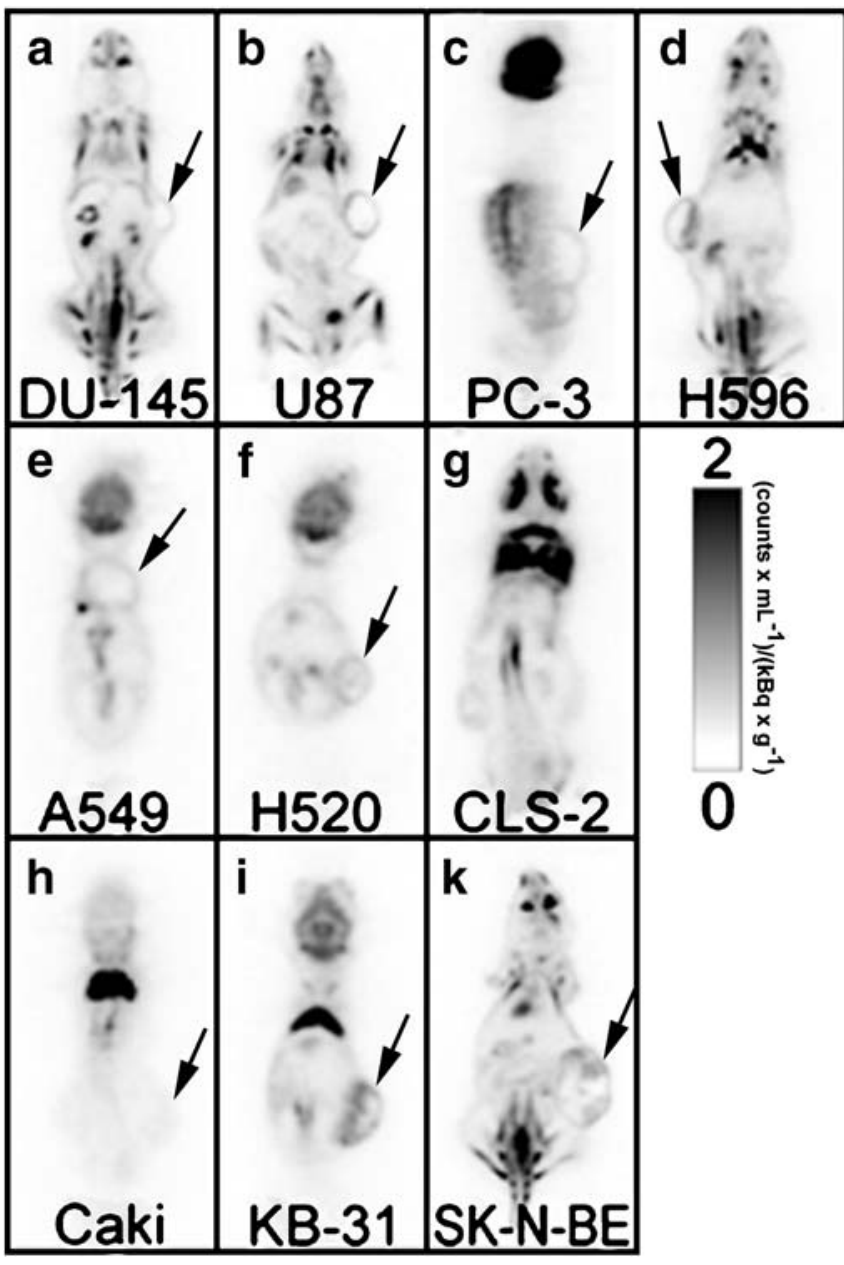

Fig. 3. Coronal NanoPET images acquired from 30 to $60 \mathrm{~min}$ after injection of $\left[{ }^{18} \mathrm{~F}\right]$ FDG. Shown are the same animals as in Fig. 1 except for the Balb/c mouse bearing B16 melanoma. The tumours are marked by arrows

Various problems such as partial volume effect and definition of exact VOIs can be minimised if a dedicated small-animal scanner with a high spatial resolution is used. A dedicated small-animal PET camera was employed only in the remaining two of the four aforementioned studies. It was shown that $\left[{ }^{18} \mathrm{~F}\right] \mathrm{FMISO}$ could be used to image tumour hypoxia in FsaII fibrosarcomas and $\mathrm{MCa}$ breast tumours [34] and in Dunning R3327-AT rat prostate adenocarcinomas in nude mice [35]. However, Zanzonico and co-workers focussed on the potential of ${ }^{124}$ I-labelled iodo-azomycin-galactoside ([ $\left.\left[{ }^{124} \mathrm{I}\right] \mathrm{IAZG}\right)$ as a hypoxia imaging agent, while Wen and colleagues aimed at developing and characterising a rodent tumour model with a reporter gene construct that would be transactivated by the upregulation of hypoxia-inducible factor-1. Due to the spatial resolution of the microPET $\left(2-3 \mathrm{~mm}\right.$ for $\left.{ }^{18} \mathrm{~F}\right)$, only limited information on the radiotracer distribution within the tumours was obtained. In contrast, the higher spatial resolution of the NanoPET (in the range of $1 \mathrm{~mm}$ for ${ }^{18} \mathrm{~F}$ ) allowed us to analyse the intratumoural heterogeneity of tracer uptake. With the exception of the Caki tumour model, the experimental tumours analysed in this study showed high TMRRs $(\geq 1.4)$. Therefore, this study suggests that hypoxia exists in the examined tumour models and supports the validity of these tumour models for the examination of therapeutic effects on tumour hypoxia by small-animal PET. However, the unrealistically high FHV values for KB-31 (>99.9\%) and H520 (100\%) in Table 1 indicate that a TMRR value of 1.4 may not appropriately define the fraction of hypoxia in murine tumour models. Using Eppendorf $\mathrm{pO}_{2}$ histograph measurements, Adam and co-workers described oxygen levels in transplanted tumour models in mice to be considerably lower than those of spontaneous human tumours [45]. Thus, it may be hypothesised that threshold values of TMRR $>1.4$ should be considered to indicate tumour hypoxia in small-animal PET studies. However, this hypothesis has to be confirmed by further experiments.

In this study, we found varying patterns of $\left[{ }^{18} \mathrm{~F}\right] \mathrm{FMISO}$ accumulation although the inoculation procedure was the same in all animals. The large intertumoural heterogeneity was accompanied by wide intratumoural variability in tracer uptake, as shown by the large standard deviations for the TMRR values in Table 1 in tumour models where several animals were examined. Most of the tumours exhibited higher concentrations of $\left[{ }^{18} \mathrm{~F}\right] \mathrm{FMISO}$ in the periphery and little activity in the centre, presumably reflecting the presence of viable hypoxic cells surrounding a central necrotic region. This assumption is supported by the work of Zanzonico and colleagues, who identified increasing necrotic fractions in large tumours $(>300 \mathrm{mg})$ [34] by histological techniques. The volumes of all tumours showing this heterogeneous uptake pattern ranged between 300 and $2,000 \mathrm{~mm}^{3}$ in our study. In some of the other tumour models, however, there were irregularly distributed foci of higher $\left[{ }^{18} \mathrm{~F}\right] \mathrm{FMISO}$ uptake and, presumably therefore, of hypoxic cells. The postulated assumption that $\left[{ }^{18} \mathrm{~F}\right] \mathrm{FMISO}$ traces viable hypoxic cells is supported by various studies $[18,43,46]$.

The great variation in the degree of $\left[{ }^{18} \mathrm{~F}\right] \mathrm{FMISO}$ uptake within a tumour prompted us to analyse additional measures for a better quantification of the heterogeneous FMISO accumulation within the tumours. Therefore, beside average TMRR values, $\mathrm{TMRR}_{75 \%}$ and $\mathrm{TMRR}_{5}$ were computed. These parameters also showed wide intertumoural differences. TMRR $75 \%$ and $\mathrm{TMRR}_{5}$ reflect the most hypoxic region of a particular tumour, but further investigations will be needed before it is possible to give a final statement on the usefulness of these parameters for the detection of tumour hypoxia in therapeutic intervention studies .

For $\left[{ }^{18} \mathrm{~F}\right] \mathrm{FMISO}$ PET imaging in mice, a scanning time of 90-120 min post injection was chosen in order to allow sufficient time for tracer clearance from normoxic tissue. This time interval appears to be adequate for the visualisation of most tumours. A similar protocol was used by Kubota and co-workers in tumour-bearing rats [47]. In our study, uptake or retention of $\left[{ }^{18} \mathrm{~F}\right] \mathrm{FMISO}$ was used to identify hypoxic regions in a tumour, and no comparison with other techniques was made. Other methods to analyse tumour hypoxia, such as post-mortem tissue studies using 
autoradiographic and histological techniques, would allow assessment of whether areas with low $\left[{ }^{18} \mathrm{~F}\right] \mathrm{FMISO}$ uptake effectively correspond to necrotic tissue. Likewise, interstitial $\mathrm{pO}_{2}$ probes (generally considered the benchmark method for in situ measurement of tissue hypoxia) or immunohistochemistry [18] would be useful for independent corroboration of the tumour oxygenation status in future studies.

Although a correlation between tumour volume and $\left[{ }^{18} \mathrm{~F}\right] \mathrm{FMISO}$ uptake was found in a single tumour model (B16 melanoma), a general relationship between tumour size and hypoxic tumour state was not identified; this is consistent with findings published in previous studies [13, 25]. Furthermore, it should be noted that defining tumour contours by radioactivity accumulation alone may result in a false estimation of tumour size. In clinical studies the combination with anatomical imaging modalities such as computed tomography provides additional information on tumour morphology.

$\left[{ }^{18} \mathrm{~F}\right]$ FMISO and other 2-nitroimidazoles undergo oxygen-reversible single-electron reduction in hypoxic environments, forming reactive radicals that subsequently bind covalently to macromolecular cellular components [48]. Since this uptake mechanism requires not only hypoxia but also intact nitroreductase enzymes [49], it is, in principle, possible to distinguish between normoxic, hypoxic viable and necrotic tissues $[9,50,51]$. However, it is still unclear whether the nitroreductase enzymes become saturated depending on the amount of unlabelled FMISO injected and therefore cause a non-oxygenation-related decline in radioactivity accumulation in a hypoxic tumour. Although a "no-carrier-added" method is employed for the preparation of $\left[{ }^{18} \mathrm{~F}\right] \mathrm{FMISO}$ and only about $2-10 \mu \mathrm{g} / \mathrm{ml}$ in total of unlabelled FMISO is obtained alongside labelled $\left[{ }^{18} \mathrm{~F}\right]$ FMISO with this method, it is of interest to know whether the effect of a high injected FMISO mass on tracer uptake can be observed in a range that is relevant for new hypoxia imaging agents, such as $\left[{ }^{18} \mathrm{~F}\right] \mathrm{EF} 5$, prepared by the "carrieradded" method [23] or for possible magnetic resonance imaging of tumour hypoxia with ${ }^{19} \mathrm{~F}$-containing 2nitroimidazoles [52]. To deal with the question of whether decreasing specific activity has an effect on $\left[{ }^{18} \mathrm{~F}\right] \mathrm{FMISO}$ uptake, we examined B16 melanoma- bearing mice using injectates with increasing amounts of unlabelled FMISO. In our studies even co-injection of no-carrier-added $\left[{ }^{18} \mathrm{~F}\right]$ FMISO with up to a thousand-fold excess of cold FMISO did not show any significant effect on tracer retention or image quality (Fig. 2). These findings are in agreement with the hypothesis of Prekeges and co-workers that nitroreductases are essentially non-saturable and should not limit the rate of FMISO reduction and uptake in hypoxic tumours [42].

It is reasonable to anticipate that hypoxia results in increased glycolysis. Hypoxia-inducible factor $1 \alpha$, which is overexpressed in response to hypoxia, is the primary transcription factor mediating a number of physiological and biological changes that include aerobic glycolysis and slowing down of proliferation [53]. Under hypoxic con- ditions in vitro, increased FDG uptake by cancer cells has been reported [54]. In vivo results from Kubota and coworkers in rats using autoradiograms [47] and PET data from Rajendran et al. in malignant human cancers [55] showed similar findings, suggesting a compensatory mechanism for the reduced delivery of glucose to the hypoxic tumour tissue by augmented tissue extraction owing to elevated glucose-transporter activity under hypoxia. Although tissue hypoxia is likely to occur as a result of reduced blood flow that causes inadequate delivery of oxygen and nutrients, we also found higher FDG accumulation in tumours demonstrating high $\left[{ }^{18} \mathrm{~F}\right] \mathrm{FMISO}$ uptake. Despite this analogous uptake pattern, it can be assumed that $\left[{ }^{18} \mathrm{~F}\right] \mathrm{FMISO}$ PET provides accessory information about tumour biology. Thus Rajendran et al. found that there can be wide variation in uptake of the two tracers [55], in accordance with the finding that FDG uptake is a function of many factors, such as microvasculature, GLUT, hexokinase expression and proliferation rate [56]. Several authors have shown that $\left[{ }^{18} \mathrm{~F}\right] \mathrm{FMISO}$ is able to identify hypoxia $[43,44,57]$, while no similar role has been found for $\left[{ }^{18} \mathrm{~F}\right] \mathrm{FDG}$.

In summary, we found that $\left[{ }^{18} \mathrm{~F}\right] \mathrm{FMISO}$ labels a variety of experimental tumours in mice, suggesting that hypoxia is common in such tumours. For the range of tumour sizes used in the current study, the spatial resolution of the NanoPET was adequate to visualise the heterogeneity of the intra-tumoural distribution of $\left[{ }^{18} \mathrm{~F}\right] \mathrm{FMISO}$. While $\left[{ }^{18} \mathrm{~F}\right]$ FMISO uptake expressed as TMRR represents a global value for the whole tumour, $\mathrm{TMRR}_{75 \%}$ and $\mathrm{TMRR}_{5}$ (in comparison with TMRR) are additional parameters that may help to adequately appraise the heterogeneous FMISO uptake in a tumour. We also demonstrated that the coinjection of $\left[{ }^{18} \mathrm{~F}\right] \mathrm{FMISO}$ with a thousand-fold greater mass of FMISO than that in the no-carrier-added $\left[{ }^{18} \mathrm{~F}\right] \mathrm{FMISO}$ injectate did not have any demonstrable effect on its tumour uptake.

Acknowledgements. We thank Paul M. McSheehy, Terence O'Reilly and Ilse Novak for providing the experimental tumour models at our disposal, Claudia Keller for important help in animal experiments and Erika Sinnig for essential laboratory work. Furthermore, the authors thank Valerie Treyer and Nicolas Späth for fruitful discussions during the writing process.

Declaration

The Swiss Federal Veterinary Office approved all experimental procedures and all animal work was performed by licensed investigators.

\section{References}

1. Adam MF, Gabalski EC, Bloch DA, Oehlert JW, Brown JM, Elsaid AA, et al. Tissue oxygen distribution in head and neck cancer patients. Head Neck 1999;21:146-53

2. Rasey JS, Koh WJ, Evans ML, Peterson LM, Lewellen TK, Graham MM, et al. Quantifying regional hypoxia in human tumors with positron emission tomography of $\left[{ }^{18} \mathrm{~F}\right]$ fluoromisonidazole: a pretherapy study of 37 patients. Int J Radiat Oncol Biol Phys 1996;36:417-28 
3. Brizel DM, Sibley GS, Prosnitz LR, Scher RL, Dewhirst MW. Tumor hypoxia adversely affects the prognosis of carcinoma of the head and neck. Int J Radiat Oncol Biol Phys 1997;38:285-9

4. Knowles HJ, Harris AL. Hypoxia and oxidative stress in breast cancer. Hypoxia and tumourigenesis. Breast Cancer Res 2001;3:318-22

5. Valk PE, Mathis CA, Prados MD, Gilbert JC, Budinger TF. Hypoxia in human gliomas: demonstration by PET with fluorine-18-fluoromisonidazole. J Nucl Med 1992;33:2133-7

6. Gray LH, Conger AD, Ebert M, Hornsey S, Scott OC. The concentration of oxygen dissolved in tissues at the time of irradiation as a factor in radiotherapy. Br J Radiol 1953;26:638-48

7. Horsman MR, Overgaard J. Overcoming tumour radiation resistance resulting from acute hypoxia. Eur J Cancer 1992;28A:717-8

8. Hockel M, Knoop C, Schlenger K, Vorndran B, Baussmann E, Mitze $\mathrm{M}$, et al. Intratumoral $\mathrm{pO}_{2}$ predicts survival in advanced cancer of the uterine cervix. Radiother Oncol 1993;26:45-50

9. Brizel DM, Scully SP, Harrelson JM, Layfield LJ, Bean JM, Prosnitz LR, et al. Tumor oxygenation predicts for the likelihood of distant metastases in human soft tissue sarcoma. Cancer Res 1996;56:941-3

10. Harris AL. Hypoxia - a key regulatory factor in tumour growth. Nat Rev Cancer 2002;2:38-47

11. Hockel M, Schlenger K, Aral B, Mitze M, Schaffer U, Vaupel P. Association between tumor hypoxia and malignant progression in advanced cancer of the uterine cervix. Cancer Res 1996;56:4509-15

12. Cater DB, Silver IA. Quantitative measurements of oxygen tension in normal tissues and in the tumours of patients before and after radiotherapy. Acta Radiol 1960;53:233-56

13. Bentzen L, Keiding S, Horsman MR, Gronroos T, Hansen SB, Overgaard J. Assessment of hypoxia in experimental mice tumours by $\left[{ }^{18} \mathrm{~F}\right]$ fluoromisonidazole PET and $\mathrm{pO}_{2}$ electrode measurements. Influence of tumour volume and carbogen breathing. Acta Oncol 2002;41:304-12

14. Achermann RE, Ohlerth SM, Rohrer Bley C, Gassmann M, Inteeworn $\mathrm{N}$, Roos $\mathrm{M}$, et al. Oxygenation of spontaneous canine tumors during fractionated radiation therapy. Strahlenther Onkol 2004;180:297-305

15. Nordsmark M, Loncaster J, Chou SC, Havsteen H, Lindegaard JC, Davidson SE, et al. Invasive oxygen measurements and pimonidazole labeling in human cervix carcinoma. Int J Radiat Oncol Biol Phys 2001;49:581-6

16. Buchler P, Reber HA, Lavey RS, Tomlinson J, Buchler MW, Friess $\mathrm{H}$, et al. Tumor hypoxia correlates with metastatic tumor growth of pancreatic cancer in an orthotopic murine model. J Surg Res 2004;120:295-303

17. Olive PL, Aquino-Parsons C. Measurement of tumor hypoxia using single-cell methods. Semin Radiat Oncol 2004;14:241-8

18. Dubois L, Landuyt W, Haustermans K, Dupont P, Bormans G, Vermaelen $\mathrm{P}$, et al. Evaluation of hypoxia in an experimental rat tumour model by $\left[{ }^{18} \mathrm{~F}\right]$ fluoromisonidazole PET and immunohistochemistry. Br J Cancer 2004;91:1947-54

19. Evans SM, Judy KD, Dunphy I, Jenkins WT, Nelson PT, Collins R, et al. Comparative measurements of hypoxia in human brain tumors using needle electrodes and EF5 binding. Cancer Res 2004;64:1886-92

20. Evans SM, Hahn S, Pook DR, Jenkins WT, Chalian AA, Zhang $\mathrm{P}$, et al. Detection of hypoxia in human squamous cell carcinoma by EF5 binding. Cancer Res 2000;60:2018-24

21. Koh WJ, Rasey JS, Evans ML, Grierson JR, Lewellen TK, Graham MM, et al. Imaging of hypoxia in human tumors with [F-18]fluoromisonidazole. Int $\mathrm{J}$ Radiat Oncol Biol Phys 1992;22:199-212
22. Ziemer LS, Evans SM, Kachur AV, Shuman AL, Cardi CA, Jenkins WT, et al. Noninvasive imaging of tumor hypoxia in rats using the 2-nitroimidazole ${ }^{18}$ F-EF5. Eur J Nucl Med Mol Imaging 2003;30:259-66

23. Dolbier WR Jr, Li AR, Koch CJ, Shiue CY, Kachur AV. $\left[{ }^{18} \mathrm{~F}\right]-$ EF5, a marker for PET detection of hypoxia: synthesis of precursor and a new fluorination procedure. Appl Radiat Isot 2001;54:73-80

24. Yang DJ, Wallace S, Cherif A, Li C, Gretzer MB, Kim EE, et al. Development of F-18-labeled fluoroerythronitroimidazole as a PET agent for imaging tumor hypoxia. Radiology 1995; $194: 795-800$

25. Gronroos T, Bentzen L, Marjamaki P, Murata R, Horsman MR, Keiding S, et al. Comparison of the biodistribution of two hypoxia markers $\left[{ }^{18} \mathrm{~F}\right]$ FETNIM and $\left[{ }^{18} \mathrm{~F}\right] \mathrm{FMISO}$ in an experimental mammary carcinoma. Eur J Nucl Med Mol Imaging 2004;31:513-20

26. Sorger D, Patt M, Kumar P, Wiebe LI, Barthel H, Seese A, et al. $\left[{ }^{18} \mathrm{~F}\right]$ fluoroazomycinarabinofuranoside $\left({ }^{18} \mathrm{FAZA}\right)$ and $\left[{ }^{18} \mathrm{~F}\right]$ fluoromisonidazole $\left({ }^{18} \mathrm{FMISO}\right)$ : a comparative study of their selective uptake in hypoxic cells and PET imaging in experimental rat tumors. Nucl Med Biol 2003;30:317-26

27. Barthel H, Wilson H, Collingridge DR, Brown G, Osman S, Luthra SK, et al. In vivo evaluation of $\left[{ }^{18} \mathrm{~F}\right]$ fluoroetanidazole as a new marker for imaging tumour hypoxia with positron emission tomography. Br J Cancer 2004;90:2232-42

28. Rischin D, Peters L, Hicks R, Hughes P, Fisher R, Hart R, et al. Phase I trial of concurrent tirapazamine, cisplatin, and radiotherapy in patients with advanced head and neck cancer. J Clin Oncol 2001;19:535-42

29. Eschmann SM, Paulsen F, Reimold M, Dittmann H, Welz S, Reischl G, et al. Prognostic impact of hypoxia imaging with ${ }^{18}$ F-misonidazole PET in non-small cell lung cancer and head and neck cancer before radiotherapy. J Nucl Med 2005;46:253-60

30. Bruehlmeier M, Roelcke U, Schubiger PA, Ametamey SM. Assessment of hypoxia and perfusion in human brain tumors using PET with ${ }^{18} \mathrm{~F}$-fluoromisonidazole and ${ }^{15} \mathrm{O}-\mathrm{H}_{2} \mathrm{O}$. J Nucl Med 2004;45:1851-9

31. Chatziioannou AF. PET scanners dedicated to molecular imaging of small animal models. Mol Imaging Biol 2002;4:47-63

32. Schafers KP. Imaging small animals with positron emission tomography. Nuklearmedizin 2003;42:86-9

33. Myers R, Hume S. Small animal PET. Eur Neuropsychopharmacol 2002;12:545-55

34. Zanzonico P, O’Donoghue J, Chapman JD, Schneider R, Cai S, Larson S, et al. Iodine-124-labeled iodo-azomycin-galactoside imaging of tumor hypoxia in mice with serial microPET scanning. Eur J Nucl Med Mol Imaging 2004;31:117-28

35. Wen B, Burgman P, Zanzonico P, O’Donoghue J, Cai S, Finn $\mathrm{R}$, et al. A preclinical model for noninvasive imaging of hypoxia-induced gene expression; comparison with an exogenous marker of tumor hypoxia. Eur J Nucl Med Mol Imaging 2004;31:1530-8

36. Lim JL, Berridge MS. An efficient radiosynthesis of $\left[{ }^{18} \mathrm{~F}\right]$ fluoromisonidazole. Appl Radiat Isot 1993;44:1085-91

37. Jeavons AP, Chandler RA, Dettmar CAR. A 3D HIDAC-PET camera with submillimetre resolution for imaging small animals. IEEE Trans Nucl Sci 1999;46:468-73

38. Missimer J, Madi Z, Honer M, Keller C, Schubiger A, Ametamey SM. Performance evaluation of the 16-module quad-HIDAC small animal PET camera. Phys Med Biol 2004;49:2069-81

39. Reader AJ, Erlandsson K, Flower MA, Ott RJ. Fast accurate iterative reconstruction for low-statistics positron volume imaging. Phys Med Biol 1998;43:835-46 
40. Mikolajczyk K, Szabatin M, Rudnicki P, Grodzki M, Burger C. A JAVA environment for medical image data analysis: initial application for brain PET quantitation. Med Inform (Lond) 1998;23:207-14

41. Bentzen L, Keiding S, Nordsmark M, Falborg L, Hansen SB, Keller $J$, et al. Tumour oxygenation assessed by ${ }^{18} \mathrm{~F}$ fluoromisonidazole PET and polarographic needle electrodes in human soft tissue tumours. Radiother Oncol 2003;67:339-44

42. Prekeges JL, Rasey JS, Grunbaum Z, Krohn KH. Reduction of fluoromisonidazole, a new imaging agent for hypoxia. Biochem Pharmacol 1991;42:2387-95

43. Gagel B, Reinartz P, Dimartino E, Zimny M, Pinkawa M, Maneschi $\mathrm{P}$, et al. $\mathrm{pO}_{2}$ polarography versus positron emission tomography ( $\left[{ }^{18} \mathrm{~F}\right]$ fluoromisonidazole, $\left[{ }^{18} \mathrm{~F}\right]$-2-fluoro-2'-deoxyglucose). An appraisal of radiotherapeutically relevant hypoxia. Strahlenther Onkol 2004;180:616-22

44. Bentzen L, Keiding S, Horsman MR, Falborg L, Hansen SB, Overgaard J. Feasibility of detecting hypoxia in experimental mouse tumours with ${ }^{8} \mathrm{~F}$-fluorinated tracers and positron emission tomography - a study evaluating $\left[{ }^{18} \mathrm{~F}\right]$ fluoro-2-deoxy-Dglucose. Acta Oncol 2000;39:629-37

45. Adam MF, Dorie MJ, Brown JM. Oxygen tension measurements of tumors growing in mice. Int J Radiat Oncol Biol Phys 1999;45:171-80

46. Piert M, Machulla HJ, Becker G, Aldinger P, Winter E, Bares R. Dependency of the $\left[{ }^{18} \mathrm{~F}\right]$ fluoromisonidazole uptake on oxygen delivery and tissue oxygenation in the porcine liver. Nucl Med Biol 2000;27:693-700

47. Kubota K, Tada M, Yamada S, Hori K, Saito S, Iwata R, et al. Comparison of the distribution of fluorine-18 fluoromisonidazole, deoxyglucose and methionine in tumour tissue. Eur J Nucl Med 1999;26:750-7

48. Nunn A, Linder K, Strauss HW. Nitroimidazoles and imaging hypoxia. Eur J Nucl Med 1995;22:265-80
49. Rasey JS, Grunbaum Z, Magee S, Nelson NJ, Olive PL, Durand RE, et al. Characterization of radiolabeled fluoromisonidazole as a probe for hypoxic cells. Radiat Res 1987;111:292304

50. Ballinger JR, Kee JW, Rauth AM. In vitro and in vivo evaluation of a technetium-99m-labeled 2-nitroimidazole (BMS181321) as a marker of tumor hypoxia. J Nucl Med 1996;37:1023-31

51. Biskupiak JE, Krohn KA. Second generation hypoxia imaging agents. J Nucl Med 1993;34:411-3

52. Seddon BM, Maxwell RJ, Honess DJ, Grimshaw R, Raynaud F, Tozer GM, et al. Validation of the fluorinated 2-nitroimidazole SR-4554 as a noninvasive hypoxia marker detected by magnetic resonance spectroscopy. Clin Cancer Res 2002;8:2323-35

53. Pedersen MW, Holm S, Lund EL, Hojgaard L, Kristjansen PE. Coregulation of glucose uptake and vascular endothelial growth factor (VEGF) in two small-cell lung cancer (SCLC) sublines in vivo and in vitro. Neoplasia 2001;3:80-7

54. Minn H, Clavo AC, Wahl RL. Influence of hypoxia on tracer accumulation in squamous-cell carcinoma: in vitro evaluation for PET imaging. Nucl Med Biol 1996;23:941-6

55. Rajendran JG, Mankoff DA, O'Sullivan F, Peterson LM, Schwartz DL, Conrad EU, et al. Hypoxia and glucose metabolism in malignant tumors: evaluation by $\left[{ }^{18} \mathrm{~F}\right]$ fluoromisonidazole and $\left[{ }^{18} \mathrm{~F}\right]$ fluorodeoxyglucose positron emission tomography imaging. Clin Cancer Res 2004;10:2245-52

56. Bos R, van Der Hoeven JJ, van Der Wall E, van Der Groep P, van Diest PJ, Comans EF, et al. Biologic correlates of (18) fluorodeoxyglucose uptake in human breast cancer measured by positron emission tomography. J Clin Oncol 2002;20:37987

57. Rajendran JG, Wilson DC, Conrad EU, Peterson LM, Bruckner JD, Rasey JS, et al. $\left[{ }^{18} \mathrm{~F}\right] \mathrm{FMISO}$ and $\left[{ }^{18} \mathrm{~F}\right] \mathrm{FDG}$ PET imaging in soft tissue sarcomas: correlation of hypoxia, metabolism and VEGF expression. Eur J Nucl Med Mol Imaging 2003;30:695704 